\title{
Histopathological Patterns of Nasal Polyps in Aseer Region, Saudi Arabia: A Retrospective Hospital-Based Study
}

\author{
KHOLOOD S. ASSIRI, M.D., SB-ORL-HNS and MOHAMMAD S. AL-AHMARI, M.D., SB-ORL-HNS
}

The Department of Otolaryngology, Khamis Mushayt General Hospital, Saudi Arabia

\begin{abstract}
Background: Nasal polyps are benign lesions that arise from the mucosa of the nasal cavity or the mucosa of nasal sinuses. Its exact etiology remains obscure. They are often bilateral and multiple, with tendency to recur. They constitute a challenge for physicians regarding its diagnosis and treatment. There are several conditions which are commonly associated with nasal polyposis, e.g., bronchial asthma and bronchiectasis.

Aim of Study: To determine the various histopathological types of nasal polyps specimens of Saudi patients who underwent surgery at Khamis Mushayt General Hospital in Aseer Region, Saudi Arabia.

Patients and Methods: Following a retrospective, hospital files-based study of 121 patients who underwent surgery to remove nasal polyps at Khamis Mushayt General Hospital during the period from 2012 to 2017, whose diagnosis was confirmed by histopathological examination. A special data collection sheet was designed by the researchers to collect patients' data from their hospital files. It included patients' personal data, i.e., gender and age, and disease-related data, i.e., laterality, recurrence, and histopathology type.
\end{abstract}

Results: More than half of patients $(58.7 \%)$ were males. Their mean age was $38.2 \pm 14.6$ years. The majority of patients $(81.8 \%)$ had bilateral nasal polyps. Nasal polyps were recurrent in $33.1 \%$ of patients. The main histopathological features of patients' nasal polyps were edematous including eosinophils $(61.2 \%)$ or fibro-inflammatory polyps $(30.6 \%)$. Rare histopathological types included angiectatic $(3.3 \%)$, glandular $(2.5 \%)$, cystic $(1.7 \%)$ and atypical stroma $(0.8 \%)$.

Conclusions: Nasal polyps among patients in Aseer Region are more common among middle-aged men. It is mainly bilateral with high recurrence rate. Their most frequent histopathological features are the "edematous including eosinophils" or "fibro-inflammatory" types. Histopathological examination of a removed nasal polyp is frequently essential to provide the actual diagnosis.

Key Words: Nasal polyps - Histopathology-Retrospective study design.

Correspondence to: Dr. Kholood S. Assiri, The Department of Otolaryngology, Khamis Mushayt General Hospital, Saudi Arabia

\section{Introduction}

NASAL polyps are benign lesions that arise from the mucosa of the nasal cavity or the mucosa of nasal sinuses. its exact etiology remains obscure. They are often bilateral and multiple, with tendency to recur [1]. They constitute a challenge for physicians regarding its diagnosis and treatment [2] There are several conditions which are commonly associated with nasal polyposis, e.g., bronchial asthma and bronchiectasis [3].

Nasal polyps are essentially rounded projections of edematous membrane above a mucosal surface and projects into lumen [4]. They are usually smooth, round, soft, translucent, yellow or pale glistening structures attached to the nasal or sinus mucosa by a relatively narrow stalk or pedicle. They are not tender and on probing become displaced backwards [5].

Medical management of nasal polyps mainly includes the use of steroids. However, in refractory cases, surgery is recommended [6]. Postoperatively, it is conventional to send specimens of the removed polyp for histopathological examination and to settle the final pathological diagnosis [7].

Rhinosinusal polyps were histologically described by Tos and Morgensen [8], as being edematous, mainly eosinophil-infiltrated myxoid stroma and covered by respiratory epithelium, which often appears with hyperplasia or squamous metaplasia. Hellquist [9] noted that there are histological differences among nasal polyps. There may be possible clinical implications of such differences, which can be important to reach a precise diagnosis.

Therefore, the present study aimed to determine the various histopathological types of nasal polyps specimens of patients who underwent surgery at 
Khamis Mushayt General Hospital in Aseer Region, Kingdom of Saudi Arabia.

\section{Patients and Methods}

This study followed a retrospective research design. It was conducted at Khamis Mushayt General Hospital, Khamis Mushayt City, Aseer Region, at the southwestern area of Saudi Arabia. The hospital files of all patients who underwent surgery to remove nasal polyps during the period from 2012 to 2017 at Khamis Mushayt General Hospital were analyzed $(\mathrm{N}=121)$.

Inclusion criteria were patients with nasal polyps aged above 12 years, whose diagnosis was confirmed by histopathological examination.

A special data collection sheet was designed by the researchers to collect patients' data from their hospital files. It included patients' personal data, i.e., gender and age, and disease-related data, i.e., laterality, recurrence, and histopathology type.

Collected data were entered into a personal computer using the Statistical Package for Social Sciences (SPSS, version 23). Descriptive statistics, i.e., frequency, percentage, mean and standard deviation were calculated.

\section{Results}

Table (1) shows that $58.7 \%$ of patients were males. Their age ranged from 13 to 85 years, with a Mean \pm SD of $38.2 \pm 14.6$ years.

Table (2) shows that the majority of patients $(81.8 \%)$ had bilateral nasal polyps. Nasal polyps were recurrent in about one third of patients $(33.1 \%)$. The main histopathological features of patients' nasal polyps were edematous including eosinophils $(74,61.2 \%)$ or fibro-inflammatory polyps $(37,30.6 \%)$. Rare histopathological types included angiectatic $(4,3.3 \%)$, glandular $(3,2.5 \%)$, cystic $(2,1.7 \%)$ and atypical stroma $(1,0.8 \%)$ types, as shown in Fig. (1).

Table (1): Patients' characteristics $(n=121)$.

\begin{tabular}{cl}
\hline Personal characteristics & Value \\
\hline Gender: & $71(58.7 \%)$ \\
Male & $50(41.3 \%)$ \\
Female & $43(35.5 \%)$ \\
Age: & $13-85$ years \\
Range & $38.2 \pm 14.6$ years \\
Mean \pm SD
\end{tabular}

Table (2): Disease characteristics $(n=121)$

\begin{tabular}{ll}
\hline Characteristics & Value \\
\hline Laterality: & \\
Bilateral & $99(81.8)$ \\
One-sided & $22(18.2)$ \\
Recurrence & $40(33.1)$ \\
Histopathology report: & \\
Edematous including eosinophils & $74(61.2)$ \\
Fibro-inflammatory Polyps & $37(30.6)$ \\
Angiectatic & $4(3.3)$ \\
Glandular & $3(2.5)$ \\
Cystic & $2(1.7)$ \\
Atypical stroma & $1(0.8)$ \\
\hline
\end{tabular}

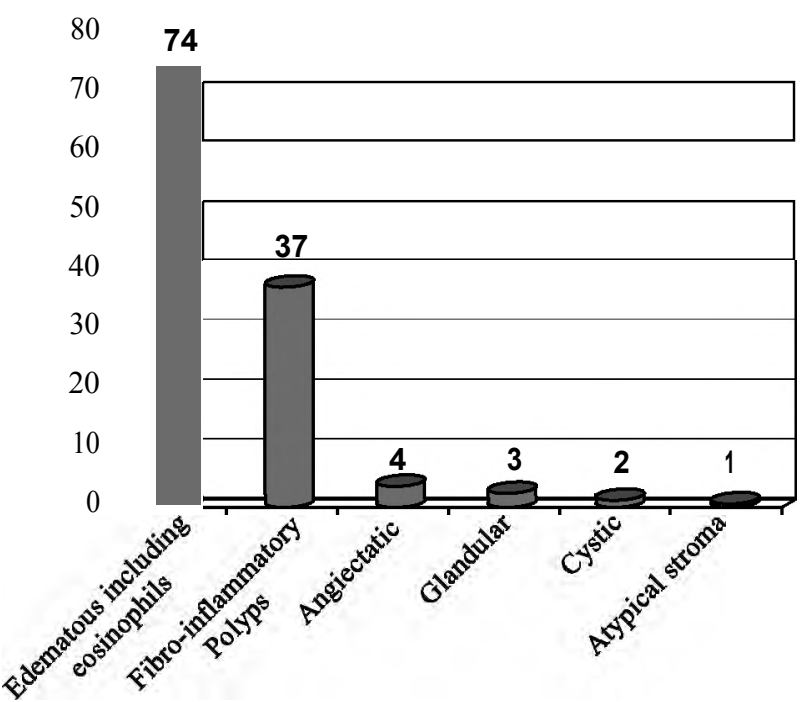

Fig. (1): Histopathological findings of nasal polyps specimens.

\section{Discussion}

Several pathologies, ranging from benign lesions to malignant nasal tumors, may mimic a simple nasal mass. Thus, it is quite impossible to determine clinically the pathology of a nasal mass. Therefore, histopathology and nasal endoscopy should be employed together to help reach the proper diagnosis. Therefore, the histopathological examination of a removed nasal polyp is frequently essential to provide the actual diagnosis [10]

The present study showed that more than half of patients were males and the patients mean age was $38.2 \pm 14.6$ years.

These findings are in accordance with those reported by several studies. Lanza and Kennedy [11] noted that nasal polyposis more commonly affects middle-aged men. In a Nigeria, Chukuezi [12]reported that the maximum presentation rate was between 31 and 40 years old. In the study of Jahromi and Pour [13], the mean age of nasal polyps patients was $39.34 \pm 16.63$ years and males were affected more than females. 
Dafale et al., [5] reported that nasal polyps occur most frequently among middle-aged males. Nonneoplastic nasal masses are usually more common in the age groups of 4 th and 5 th decades, while neoplastic masses are more common among patients in the 5 th or 6 th decades $[14,15]$

Findings of the present study showed that the majority of patients had bilateral nasal polyps and the polyps were recurrent in about one third of patients.

Mygind et al., [16] stated that recurrent, multiple nasal polyps, constitute a part of an inflammatory reaction that involves the mucous membranes of the nose, paranasal sinuses, and often the lower airways. Nasal polyps commonly occur in patients with intolerance to aspirin and those with allergic fungal sinusitis. These two conditions are characterized by an eosinophil-dominated inflammation as a common feature, and the degree of tissue eosinophilia appears to be an important factor in recurrence rate for nasal polyposis.

Tritt et al., [17] reported that $84.7 \%$ of patients with nasal polyps had bilateral polyps. They stressed that, when nasal masses are unilateral, benign or malignant pathologies should be decided by nasal endoscopy, CT-scan, and biopsy for histopathology.

The main histopathological features of nasal polyps among our patients were "edematous including eosinophils" or "fibro-inflammatory" polyps. However, other rare histopathological types included "angiectatic" type, "glandular" or "cystic" type and "atypical stroma".

These findings are in accordance with those of Couto et al., [18], who reported that edematous or eosinophilic polyps predominated. Next, it was followed by the fibroinflammatory pattern. Hyperplasia of seromucinous glands were less prevalent, while polyps with stromal atypia constituted the rarest type.

Kakoi and Hiraide [19] stated that histologically, nasal polyps can be classified into three types, i.e., edematous; glandular and cystic type (ductal type) or the fibrous type. Polyps of the edematous type and the glandular and cystic type are in the active stage of tissue reaction with permeation of vascular fluid and marked infiltration of round cells. On the other hand, the fibrous type nasal polyps are in the healing stage of tissue reaction because of marked proliferation of fibroblasts and collagen fibers. They added that morphological structures of the nasal glands involved in the bulging mucosa determines the type of nasal polyps, whether edematous type or glandular and cystic type.

Pawanker [20] stated that the presence of mast cells and eosinophilia within nasal polyps provide evidence suggesting that inflammation is a major factor in polyp formation.

Nota et al., [21] noted the angiectatic nasal polyps are rare. They are usually found as an inflammatory sinonasal polyps, accounting for 4$5 \%$ of all nasal polyps. They usually originate from the maxillary sinus mucosa, and enlarge gradually without provoking any symptoms.

Batsakis [22] reported that nasal polyps with atypical stroma indicate a peculiar response in fibroblasts or fibrohistiocytes to increased intercellular fluid and/or vascular compromise. It is important to adherence to established histologic criteria to eliminate misjudging these cytologic changes as sarcomas.

In conclusion, nasal polyps are more common among middle-aged men. It is mainly bilateral with high recurrence rate. Their most frequent histopathological features are the "edematous including eosinophils" or "fibro-inflammatory" types. Other less common histopathological types include "angiectatic" type, "glandular" or "cystic" type and "atypical stroma".

Since it is difficult to determine clinically the pathology of a nasal mass, histopathological examination of a removed nasal polyp is frequently essential to provide the actual diagnosis.

\section{References}

1- MARU A.M., PATEL U.V., SHRIVASTAV A., LAKUM N.R., CHOKSI T.S. and AGNIHOTRI A S.: Histopathological study of nasal masses in patients coming to a tertiary care hospital: A study of 70 cases. Med. J. DY. Patil. Univ., 8: 468-473, 2015.

2- DAS A., BAL A., CHAKRABARTI A., PANDA N. and JOSHI K.: Spectrum of fungal rhinosinusitis; histopathologist's perspective. Histopathology, 54: 854-9, 2009.

3- NEWTON J.R. and AH-SEE K.W.: A review of nasal polyposis. Therapeutics and Clinical Risk Management, 4 (2) 507-512, 2008.

4- MARK W.L. and KUMAR V.: In: Kumar V., Abbas A.K., Fausto N., editors. Robbins and Cotran Pathologic Basis of Disease. 7 th ed. Pennsylvania: Elsevier, p. 773-796, 2004.

5- DAFALE S.R., YENNI V.V., BANNUR H.B. and MALUR P.R.: Histopathological study of polypoidal lesions of the nasal cavity. Al Ameen. J. Med. Sci., 4: 403, 2012.

6- DESROSIERS M., EVANS G.A., KEITH P.K., WRIGHT E.D., KAPLAN A., BOUCHARD J., et al.: Canadian clinical practice guidelines for acute and chronic rhinos- 
inusitis. J. Otolaryngol. Head. Neck. Surg., 40 (Suppl 2): S99-193, 2011.

7- YEH D.H., WONG J., HOFFBAUER S., WEHRLI B., SOMMER D. and ROTENBERG B.W.: The utility of routine polyp histopathology after endoscopic sinus surgery. Int. Forum. Allergy. Rhinol., 4: 926-30, 2014.

8- TOS M. and MORGENSEN C.: Pathogenesis of Nasal Polyps. Rhinology, 15: 87-95, 1977.

9- HELLQUIST H.B.: Histophatology. Allergy and Asthma Proc., 17 (5): 237-42, 1996.

10- CHOPRA H., DUA K., CHOPRA N. and MITTAL V.: Histopathology of nasal masses. Clinical Rhinology: An International Journal, 3 (2): 81-85, 2010.

11- LANZA D.E. and KENNEDY D.W.: Current concepts in the surgical management of nasal polyposis. J. Allergy. Clin. Immunol., 90: 543-6, 1992.

12- CHUKUEZI A.B.: Nasal polyposis in Nigerian district hospital. West. Afr. J. Med., 13 (4): 231-3, 1994.

13- JAHROMI A.M. and POUR AS.: The Epidemiological and Clinical Aspects of Nasal Polyps that Require Surgery. Iran J. Otorhinolaryngol., 24 (67): 75-78, 2012.

14- KIRTSREESAKUL V.: Nasal polyps: The relationship to allergy, sinonasal infection and histopathological type. J. Med. Assoc. Thai., 87: 277-282, 2004.
15- KITAPÇI F., MULUK N.B., ATASOY P. and KOÇ C. Role of mast and goblet cells in the pathogenesis of nasal polyps. J. Otolaryngol., 35: 122-32, 2006.

16- MYGIND N., DAHL R. and BACHERT C.: Nasal poly posis, eosinophil dominated inflammation, and allergy. Thorax., 55 (Suppl 2): S79-S83, 2000.

17- TRITT S., MCMAIN KC. and KOUNTAKIS S.E.: Unilateral nasal polyposis: Clinical presentation and pathology. Am. J. Otolaryngol., 29 (4): 230-2, 2008.

18- COUTO L.G.F., FERNADES A.M., BRANDÃO D.F., NETO D., VALERA F.C.P. and ANSELMO-LIMA W.T.: Histological aspects of rhinosinusal polyps. Rev. Bras. Otorrinolaringol., 74 (2): 207-212, 2008.

19- KAKOI H. and HIRAIDE F. A.: Histological Study of Formation and Growth of Nasal Polyps, Acta OtoLaryngologica, 103 (1-2): 137-144, 1987.

20- PAWANKER R.: Nasal polyposis: An update. Curr. Opin. Allergy. Clin. Immunol., 3 (1): 1-6, 2003.

21- NOTA J., HINOHIRA Y., TAKAHASHI H., WATANABE F. and GYO K.: Angiectatic Nasal Polyp Localized in the Maxillary Sinus. Japanese Journal of Rhingology 47 (2): 105-108, 2008.

22- BATSAKIS JG.: Pathology consultation: Stromal cell atypia in sinonasal polyposis. Ann. Otol. Rhinol. Laryngol. 95: 321-322, 1986.

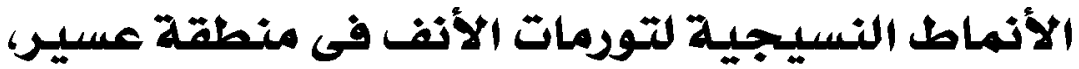

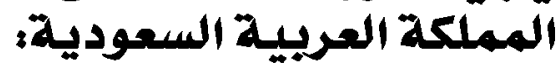

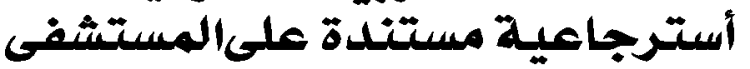
هدف الدراسة: تحديد الأنواع النسيجية المختلفة لعينات تورمات الأنف لدى المرضى السعوديين الذين أجريت لهم الجراحة

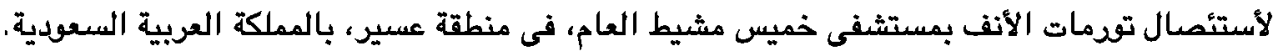

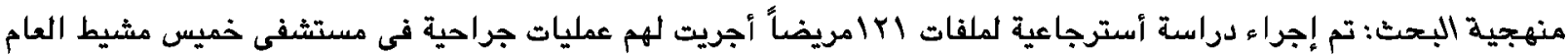

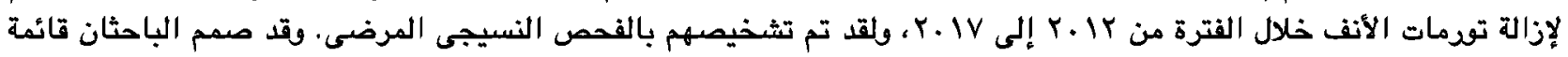

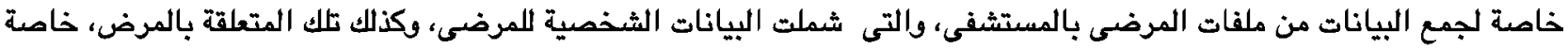 النمط النسيج المرضى للتورمات الأنفية.

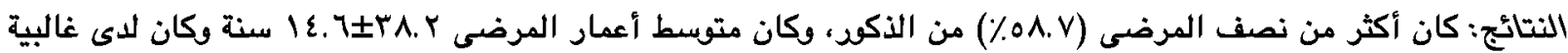

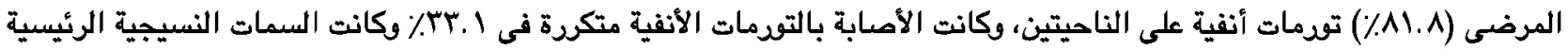

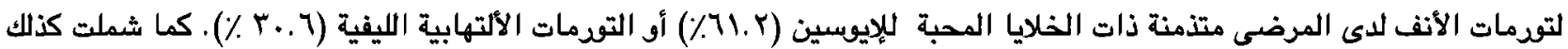

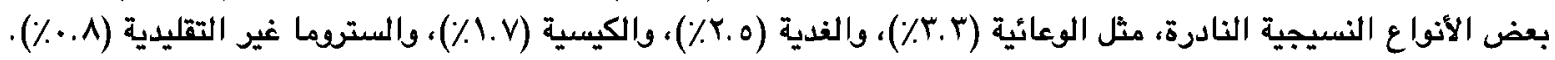

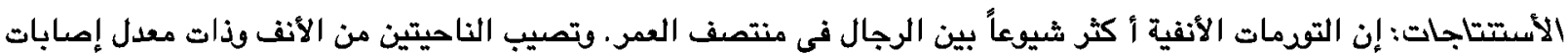

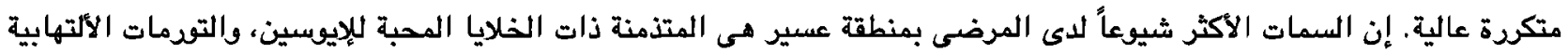

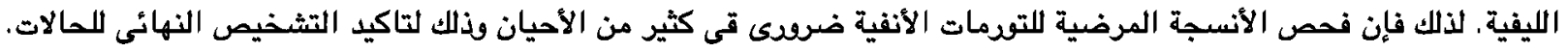

